\title{
El imaginario de Valparaíso a mediados del siglo XX en Sabadomingo, novela de Juan Uribe, y en De carne y sueño, memorias de Alfredo González ${ }^{1}$
}

\author{
Imaginary of Valparaiso in the Mid Twentieth Century \\ in Juan Uribe's Novel Sábadomingo and in the \\ Memories of Alfredo González, De carne y sueño
}

\author{
Adolfo de Nordenflycht \\ Pontificia Universidad Católica de Valparaíso, \\ Instituto de Literatura y Ciencias del Lenguaje. Valparaíso, Chile \\ adnorden@ucv.cl
}

Resumen • En este trabajo se revisa como la novela Sabadomingo de Juan Uribe y De carne y sueño, memorias de Alfredo González, presentan un imaginario de la decadencia de Valparaíso, asumido desde la paratopía de la bohemia. Este imaginario se comprende como una subversión a la modernidad transplantada, que se correspondió con el imaginario prometeico de los filántropos y los activistas ácratas de las primeras décadas del siglo XX. Las representaciones de Valparaíso que construyen Uribe y González revelan, de un modo socarrón y provocador, la declinación de la identidad local prometeica, pero también manifiestan que la decadencia no supone otro imaginario, sino que es un refinamiento del mismo, que propicia la subversión.

Palabras clave: imaginario local, narrativa de Valparaíso, paratopía, espacio, identidad.

\begin{abstract}
The present work reviews the way in which Juan Uribe's novel Sabadomingo and the memoirs De carne y sueño by Alfredo González present an imaginary of decadence of Valparaíso, assumed from the bohemian paratopia. This imaginary is understood as a subversion against a transplanted modernity, which correspond to the promethean imaginary of philanthropists and anarchists of the first decades of the twentieth century. The representation of Valparaíso that both Uribe and González construe reveals, in a mocking and provocative way, the decline of the local promethean identity. Also the authors convey that decadence is not another imaginary but a refinement of the one given which favors subversion.
\end{abstract}

Keywords: local imaginary, narrative of Valparaíso, paratopia, space, identity.

Proyecto núm. 1085201: «Constelaciones del imaginario local en la literatura de Valparaíso $(1888,1989)$ : Procedencias y emergencias para una historia efectiva», financiado por el Fondo Nacional de Ciencia y Tecnología, FONDECYT. Responsable de la investigación, Adolfo de Nordenflycht. 


\section{NOVELA Y MEMORIAS LOCALES, COMO ESCENOGRAFÍAS DE IDENTIDAD}

Señaladas como literaturas subnacionales, regionales, territoriales o locales, se han articulado, en tanto exponentes de inciertas discursividades, conjuntos de textos, parcialmente reconocidos, pero que a menudo también han sido relegados o excluidos del canon nacional. En el caso de Chile, tales literaturas, con denominaciones variables (como «poetas del sur», "novela magallánica», «literatura maulina», etc.) se han construido, por lo general, aplicando modelos historiográficos simplificados, vagamente generacionales o trasladando de manera mecánica una perspectiva totalizadora y homogeneizante provista desde la noción de una literatura nacional, pergeñada en la metrópolis. No ha sido distinto el caso de la denominada "literatura de Valparaíso", a pesar de que uno de sus historiógrafos señale que "Valparaíso y Santiago son dos países diferentes cuando se trata de hablar de literatura. Cada uno tiene la suya. Dejémoslo así. Es lo que justifica estas anotaciones para una Historia Aparte» (Solar, 2001: 6). Aunque el crítico no vuelve a insistir en su calificación, creo que se podría entender que una historia aparte no es solo una historia diferenciada, sino que también una historia «en otro lugar». En efecto, estas literaturas de regiones subnacionales, resultan de una otra forma determinadas por rasgos referenciales e identitarios asociados a un «otro lugar», al espacio local. Y es esta condición la que, frente al desdibujamiento de las identidades nacionales en el tumulto de la globalización, ha potenciado un resurgido interés por las manifestaciones de identidades locales y fragmentadas que se reclaman en el despliegue de comunidades que antes fueran avasalladas por el proyecto modernizador y sus secuelas.

Las comunidades locales, las regiones (espacios culturales de arraigo), entre otras, parecen así ir visibilizándose en un rearticulado escenario de lo público y con ello han comparecido también esas literaturas que hasta el momento figuraban apenas como clasificaciones sumergidas o subordinadas en la historia literaria nacional; lo cual viene posibilitando que se revelen otros textos, o bien se planteen relecturas desde una perspectiva que destaca cómo las identidades locales son recreadas, representadas y tensionadas en el ámbito reoriginador de las escrituras producidas en las regiones, provincias, localidades, en buenas cuentas, en un espacio directamente vivido y asociado a imágenes-símbolos locales y que es el núcleo de las experiencias interconectadas del espacio experimentado y sede de la memoria identitaria, la que a su vez lo construye a través de un amasijo de experiencias y discursos propios y ajenos, individuales y colectivos, contemporáneos o anteriores, reales o imaginarios. Se trata de lo que Augé (1992) reconoce como «lugar», determinado por una historia y unas relaciones particulares, configurado por identidades individuales que se articulan mediante lenguajes, referencias locales y reglas implícitas, para constituir un escenario existencial, que siendo a la vez concreto y simbólico, es generador, pero también generado por experiencias compartidas.

Entre las escrituras del lugar se sitúan la novela regional o de provincia y las memorias locales, narrativas ambas que pueden bien incluirse como constituyentes constructivos, no exclusivos, de lo que Robin llama la «novela memorial colectiva» (1989: 69); aquello que la gente de la localidad recuerda y conserva de su trajinar por la existencia y de lo que le comunicaron sus mayores. Frente a la historia, sea oficial o alternativa, que da cuenta de los cambios sociales, explicándolos o justificándolos, la «historia vivida» (González, 2008: 9) se interesa por lo que aparentemente no cambia, por lo que permanece, por la existencia local, en la que no hay acontecimientos (que son afecciones de cambio y por 
ello sucesos históricos), sino solo haceres que se repiten, como ha señalado Bajtin (1981: 247) a propósito del cronotopo flaubertiano, y por ello es construida en y por la memoria. Si la historia ha devenido nacional, la memoria es el proceso correspondiente a los haceres locales. La memoria colectiva local, y tal vez por ello acoge entre sus constituyentes a la novela provinciana y las memorias locales, es novelesca, en tanto no es cronológica ni es un pasado fijo, sino una experiencia viviente, que "opera como los recuerdos por imágenes sucesivas, por asociaciones, que mezcla lugares y fechas, que confunde e imbrica varios eventos en uno solo o los fractura, esconde o silencia» (Uribe, 1993); su tiempo-espacio es local, simbólico y acrónico, es el lugar de las historias de vida, de lo testimonial, de las tradiciones, leyendas y mitos urbanos, de los pequeños relatos, de los personajes, las agrupaciones y espacios subalternos, las fantasías y las ilusiones, que historiza, pero también fabula, inventa, elude o silencia de acuerdo con una estrategia identitaria de persuasión y resistencia. La novela memorial colectiva trabaja con los materiales de la memoria y el imaginario individual, manifestados en las novelas locales y las memorias personales, entre otros textos locales, los que a su vez son, en tanto literatura menor, enunciadas desde lo colectivo, marcadamente políticas y, paradójicamente, desterritorializadas (Deleuze y Guattari, 1978: 28-30). Paradoja que puede explicarse si se acepta que, según Renato Ortiz (1996: 63), la desterritorialización viene acompañada de una re-territorialización que actualiza el espacio como dimensión social, en la cual el plano de lo local es definido como el espacio de diferencialidad de cada cultura.

La solidaridad entre la memoria colectiva y el imaginario individual es la que permite reconocer que los textos literarios locales vengan a robustecer la identidad, ofreciéndole sentido a las comunidades locales, al servir como señas de referencia para su despliegue y reconocimiento, en la medida que descubren, construyéndolos, los mitos identitarios que le dan significación al quehacer sociocultural de una entidad territorial (ciudad, comarca, provincia, región) en los diferentes momentos de su desarrollo, pues se trata de relatos que insistiendo sobre lo real vienen a dar corporeidad a los imaginarios involucrados en el tejido de las prácticas cotidianas del lugar, de sus proyectos, sus estrategias y conducciones, pero también sus temores y sus fantasmas.

Las escrituras memoriográficas y las novelas locales podrían considerarse como tipos discursivos privilegiados para examinar las fluctuaciones y mediaciones entre la construcción del sujeto y la identidad colectiva locales, considerando que dichos textos son percibidos como construcción imaginada producto de una práctica de pertenencia a grupos locales con los que se comparten las normas de generación del sujeto social y las representaciones del pasado y el presente del lugar y que al no tener pretensiones de dar cuenta de una subjetividad sobresaliente o de relatar acontecimientos descollantes y ejemplificadores, se orientarían sobre todo a consignar «la positividad de un lugar sobre el que se articula el discurso, pero sin reducirse a ello» (De Certau, 1995: 72). Sin reducirse a ello, pues no puede dejarse de lado la intención literaria de las memorias de González y de la novela de Uribe, y por tanto en ellas, como afirma Maingueneau:

la enunciación literaria desestabiliza la representación que se hace comúnmente de un lugar, con un adentro y un afuera. De hecho, los «milieux» literarios son fronteras. La existencia social de la literatura supone, a la vez, la imposibilidad de cerrarse sobre sí misma y de confundirse con la sociedad «ordinaria» (1993: 29). 
De allí su funcionamiento intersticial, que no es la ausencia de todo lugar, sino una «difícil negociación entre el lugar y el no lugar, una localización parasitaria que vive de la propia imposibilidad de estabilizarse. A esta localidad paradojal la llamaremos paratopía» (29). Según las épocas, los países, las regiones, la paratopía adquiere fisonomías muy diversas. El enunciado literario, sostiene más adelante Maingueneau (123-4), implica un contexto, pues el enunciador se inscribe necesariamente en un tiempo y un espacio que comparte con el receptor. Por lo tanto hay que tomar en cuenta la situación de enunciación, la «esceno-grafía» (conformada por una «cronografía», un momento, y una «topografía», un lugar) que el texto presupone y que a su vez valida. Al ser condición y producto, estar en y fuera de la obra, la escenografía constituye el articulador privilegiado entre obra y mundo.

Apoyándonos en estos planteamientos postulamos que, junto al efecto estético o artístico, tanto las memorias locales como las novelas locales articularían una escenografía desde cuya consideración se perciben con un propósito instrumental: como la posibilidad salvadora ante un medio hostil, de marginación y de pérdida. La apuesta permanente del memoriógrafo y el novelista territorial parece ser que esta modalidad escritural local, permitirá la recuperación identitaria del sujeto en un proceso de construcción imaginaria de ese otro que es su entorno.

\section{VALPARAÍSO EN LAS MEMORIAS DE GONZÁLEZ Y EN LA NOVELA DE URIBE}

González y Uribe son "casi españoles», coetáneos y se conocieron sin duda en el ámbito de la colonia española de Valparaíso (la Casa Vasca, el Centro Español) y en las tertulias de la bohemia porteña que se reunía en la Casa del Artista que ambos solían frecuentar. El primero, aunque nacido en Valparaíso en 1912, es hijo de un comerciante asturiano y una acomodada madrileña que vinieron a Chile escapando de unos padres que miraban con muy malos ojos ese matrimonio. Alfredo González se desempeñó como ayudante de comercio en el negocio de un tío y no hay noticia de que alguna vez haya viajado fuera de Valparaíso. Escritor aficionado de poesía y relatos inéditos, su gran pasión fue el teatro, y al parecer escribió varias obras, sin que ninguna de ellas fuera estrenada. Quienes lo conocieron, señalan que fue uno de esos grandes conversadores que en cualquier bar del Valparaíso de esos tiempos, acompañado de una copa de vino y de un grupo de amigos, pasaba el tiempo hilvanando las anécdotas y personajes (entre los que se encuentra Uribe) que concluyeron formando parte de su único libro publicado, cinco años después de su muerte: De carne y de sueño (1995), subtitulado como Memorias del Valparaíso de ayer, un ayer que corresponde aproximadamente a los años entre 1930 y 1960. Por su parte, Juan Uribe nació en Guecho (Bilbao) en 1908, pero llega a Chile siendo niño. Su actividad como profesor universitario de literatura y como investigador de las tradiciones chilenas, en particular de las fiestas, los juegos, los deportes y la poesía popular, es bastante conocida a través de sus numerosas publicaciones, por lo que no es necesario referirse a ella. Para nuestro propósito solo nos interesa destacar su relación con Valparaíso, puesto que se trata de uno de esos autores que no solo hicieron una pasantía en Valparaíso, sino que encallaron en el puerto, al que arriba en 1934 como profesor del liceo Eduardo de la Barra hasta 1943 y luego del 1950 al 1960, año en que se jubiló como profesor de literatura moderna del Instituto Pedagógico de Valparaíso. Sabadomingo (1973), su segunda y 
última novela, tiene como protagonista a Pedro Maturana, un profesor del Liceo porteño hacia finales de los años 30, una suerte de alter ego del autor. El episodio de la llegada del Winnipeg a Valparaíso, el inicio de la segunda guerra mundial y las discusiones sobre los nazis y los aliados ante las pizarras de los periódicos porteños, las referencias, escasas y precavidas, sobre la guerra española y la dictadura franquista, sitúan los acontecimientos locales en el marco histórico mundial. Recordamos estos datos biográficos, pues dicen mucha relación con el espacio local de Valparaíso que revelan ambos textos.

Ni Uribe ni González son hombres a los que seduzca el mar ni la actividad marítimaportuaria, tampoco son escritores del litoral, al acercarse al mar una ola moja los zapatos del profesor Maturana causando la hilaridad de los pescadores, y apenas una vez se apunta en Sabadomingo que Maturana y el poeta Galdames se sentaban a conversar frente al mar cerca de la Caleta Portales. Maturana ve el mar desde lejos, desde los cerros, por los que deambula como un paisaje distante. El puerto ha quedado para los ingleses, los alemanes y sus descendientes que manejan el tráfico marítimo y para los marineros de los navíos extranjeros o nacionales que lo ocupan momentáneamente. El Valparaíso de que hablan estos autores es el del "plan", del que los referentes mar y cerro, con que normalmente se sitúa el transeúnte, quedan silenciados, casi desaparecidos en una arquitectura bizarra y surrealista, como la moteja Uribe. En la narrativa de estos autores, como también en la de Carlos León, entre otros, puede apreciarse un Valparaíso que está al margen del pintoresquismo y el localismo oficializado, al margen del imaginario del Valparaíso de las quebradas fundadoras de una ciudad sin fundación y sin gentilicio (apenas porteños, por lo de puerto... de Santiago), tampoco el imaginario de acero, de los ascensores, ferrocarriles y vapores del auge del Valparaíso moderno y progresista de la oligarquía comercial y filantrópica decimonónica en la que nace Joaquín Edwards (auge finiquitado con la apertura del Canal de Panamá, el salitre sintético, el desarrollo urbano del balneario viñamarino, la aeronavegación y el crack de las bolsas de 1929) y tampoco del Valparaíso «imaginista», articulado en autores como Salvador Reyes, Luis Enrique Délano, Jacobo Danke, que se encontraron con la ciudad para sus narrativas aventureras y la ciudad los encontró a ellos en un momento de crisis, de vaciamiento identitario, y que con el fin del viaje de aventura terminó cuajando en un pintoresquismo melancólico). La ciudad de González y Uribe es un Valparaíso que se ha extendido urbanísticamente hacia el Almendral, antiguo espacio de huertas y quintas, y que durante el siglo XIX va siendo poblado por comerciantes enriquecidos y gravita por unos decenios como polo del asentamiento aristocrático, que luego se traslada a Viña del Mar y a Santiago, dejando el Almendral a los emigrantes españoles, palestinos e italianos que instalaron sus comercios consolidando el plan del Almendral como un barrio de clase media y artesanado, que extiende el centro comercial que se había ya trasladado al sector sureste del puerto por las calles Esmeralda, Condell y el entorno de la Plaza Victoria y la avenida Pedro Montt. González y Uribe escriben sobre un Valparaíso que ha dado la espalda al mar, y al paisaje natural del entorno (Sabadomingo empieza señalando "Nadie parecía prestar mucha atención a la belleza de aquella tarde de septiembre...» (7); las memorias de González, por su parte, se inician describiendo una procesión en que todos fijan la vista en un punto lejano, esperando ver el milagro de la aparición de la Virgen por los ojos de otros, pero sin prestar atención a «las fragancias de romero, hierbabuena, menta, toronjil y boldo» (13) de la quebrada por donde asciende la multitud). Es una escritura que, alejada del puerto y su actividad mercantil, naviera y cosmopolita, parece «aprovinciarse» en el Almendral y sus personajes acuartelarse en los bares, tabernas y pensiones. 
Ambos textos discurren con cierta nostalgia sobre un pasado, un «ayer», que parece percibirse con la distancia como un mundo irrecuperable, más rico humanamente, más lleno de solidaridad y de emociones simples, pero nobles. La cortina metálica casi cerrada de la boite "Café Checo" que deja pasar apenas un filo de la luz del amanecer en el final de Sabadomingo (dentro de la boite quedan recluidos de manera voluntaria los últimos bohemios noctámbulos, un Valparaíso que ya no será más; afuera, como si se tratara de otro mundo, empieza a amanecer) y el ilusorio regreso ritual a la patria natal de los misóginos españoles, en el paseo dominical a las afueras de Valparaíso, donde «terminaría Chile», con que González cierra sus memorias, revelan la clausura y la añoranza de ese mundo. Sin embargo, los personajes que pueblan dicho mundo son seres frustrados, desencantados, derrotados, que entre juerguistas y calaveras asumen de artistas que deambulan por espacios degradados, tabernas, pensiones y restaurantes de mala muerte entregándose a una bohemia provinciana; bohemia marginada, escenografía desde la que se enuncia el relato de cómo el tiempo de la ciudad se vacía y se repite casi inmovilizándose, puesto que lo que efectivamente se revela en estos dos textos no corresponde a las peripecias, más o menos anecdóticas y pintorescas, pero en sí mismas insignificantes, sino que un diferente estadio del imaginario de Valparaíso que ya no es un imaginario proyectivo sino que un imaginario defensivo signado por el tiempo de la decadencia y consecuentemente nostálgico del esplendor y pujanza del siglo XIX.

Sabadomingo, con una débil trama que se estructura en torno al deambular del profesor Maturana por Valparaíso, primero por las cantinas de pescadores y matarifes, en las que encuentra un paliativo para su soledad y su angustia haciendo amistad con el poeta Galdames, quien iba a esos lugares «solo a cargar el subconsciente, profesor, a confraternizar con mis elementos poéticos. Claro que también me gustan el vino y la gente del pueblo» (21) (personaje en el que es fácil reconocer al poeta porteño Guillermo Quiñónez, autor del extenso poema La galleta marinera) y luego fraguando un simulado encuentro casual con la joven y atractiva viuda con que cambiara unas palabras en una modesta librería y que lo dejó literalmente con mal de amor, permite que los espacios representados con detalle y realismo descriptivo resulten casi fotografías etnográficas del Valparaíso de los años 30, sus hábitos recreativos, sus personajes típicos y los legendarios del folklore urbano porteño. Fotografía de una época en la que será principalmente la proteica mitología de la bohemia la que da ocasión y figura a la conflictuada inserción del escritor, como lo evidencian las memorias y la novela que en varias ocasiones narran las mismas anécdotas y hacen intervenir a los mismos personajes. La ambigüedad de la paratopía bohemia tiene como espacio el bar, la taberna, también el burdel, donde el escritor y el artista, como señala Maingueneau:

es a la vez el impuro y la fuente de todo valor, el paria y el genio, según la ambivalencia del sacer latino, maldito y sagrado. En la frontera de la sociedad ordenada, el artista es aquel en que se mezclan peligrosamente las fuerzas maléficas y benéficas. (1993: 36).

En la frontera de la sociedad ordenada, el artista se acuartela en un reducto donde la nobleza de las pautas de conducta humana, la amistad, la fraternidad, la solidaridad, el respeto al contradictor, las señas de identidad, resisten al nuevo orden homogeneizador y tecnificado del presente, pero corrompido y engañoso. Esta condición escenográfica parece revestir los textos de González y de Uribe. 


\section{LUGAR E IDENTIDAD: «CORRIENTE DE AIRE» Y «GATOS CASTRADOS»}

Desde la paratopía de la bohemia porteña, ser de Valparaíso - a mediados del siglo $\mathrm{XX}$ - es alejarse del centro de la actividad moderna, por tanto, es volverse decadente y fuera de vigencia. Afirma González:

Valparaíso no servía para ciudad moderna, y los urbanistas aficionados creían que para lograrlo bastaba con echar abajo la antigua y noble arquitectura. Valparaíso quedó convertido en una corriente de aire (62, el destacado es nuestro).

A partir de aquí, la operación identitaria se afirma en la explícita imagen de referencia (el poeta, sea Galdames en la novela, o directamente Quiñones en las memorias) y la descripción de las formas de enfrentar la vida: las ensoñaciones, los idilios, las extravagancias, el vagabundeo por los espacios populares, las conversaciones en los bares y el dislate.

Sabadomingo emplaza un narrador que se detiene en la elaboración de descripciones detalladas de la vida cotidiana, en especial de juegos y deportes populares (que también interesaron a Uribe en sus estudios del folklore) como las carreras de caballo, la riña de gallos, el boxeo, construyendo estas actividades como escenas espectaculares y abigarrados cuadros sembrados de una proliferante multitud de personajes típicos (apostadores, preparadores, jinetes, boxeadores), y de fugaces protagonistas populares que apenas se resuelven en un boceto rápido o una anécdota efímera, a la manera de Baroja (que es uno de los autores preferidos de Uribe). En cierta medida, estas representaciones tienen algo de escenas costumbristas pero también de la observación etnográfica o sociológica. De aquí que el punto de vista adoptado, que se sitúa entre la omnisciencia autorial y la neutral, resulta caracterizado por una tendencia a la explicación, que sin embargo no le impide ironizar, estableciendo una distancia entre el mundo narrado y el narrador, y consecuentemente convirtiendo al lector en su cómplice. Por momentos puede observarse una inclinación a la focalización en el protagonista (particularmente cuando deambula por calles y cerros de la ciudad), pero en general el narrador siempre se reserva el derecho a controlar su relato de vocación realista que evidencia una aguda observación de las costumbres sociales descritas con concisión y detalles sugerentes. La lasitud de la trama deriva en una estructuración discontinua y fragmentada que desperdiga la novela a tal grado que muchos de los fragmentos que la componen podrían estar en otro orden sin que se modificara el conjunto en demasía, lo cual deja de manifiesto que el propósito de la novela se orienta sobre todo a la representación mimética del Valparaíso de la época, incluyendo abundantes anécdotas tomadas de la realidad, ciertos hechos de la historia local (como el arribo del Winnipeg trayendo el exilio republicano) y personajes apenas distanciados de sus modelos. El Valparaíso representado por Uribe no es únicamente un espacio escénico, por momentos fascinante y seductor, en el que entran y salen personajes en continua dispersión y por donde el protagonista transita aguardando el reencuentro con la mujer que lo ha cautivado y que termina siendo apenas la excusa para haber recorrido de un lado a otro la ciudad. Pero también Sabadomingo sintetiza, en los espacios de las tabernas de matarifes y pescadores, los bares de la bohemia, las boites, burdeles y pensiones, lugares de juego y apuestas, un hábitat de seres postergados y perdedores que sobrellevan con actitudes muchas veces extravagantes y desmesuradas la experiencia 
existencial de no-pertenencia a la cultura de la oligarquía empresarial progresista y modernizadora, que caracterizó al puerto decimonónico y que se ha vuelto una realidad fantasmal (el gran comercio, las pujantes empresas, la modernidad, abandonaron Valparaíso y se han trasladado a la capital), que provoca añoranza en algunos, melancolía en otros y decadencia en todo. De modo que el ámbito de los excluidos existe como los márgenes de una ausencia y su insistencia en ello es la marca de lo decadente. Al respecto no deja de ser una irónica alegoría de la situación de la ciudad el relato que se hace, en el primer capítulo de la novela, sobre la «temporada chica» de carreras hípicas, en la que se acude al hipódromo (Sporting Club de Viña) a apostar sobre carreras que se corren en Santiago y son trasmitidas telefónicamente:

Era divertido, pero también bochornoso. Jamás hubiera creído que iba a llegar a la apuesta telefónica, arriesgando su dinero en algo que no presenciaba, en las contingencias de una carrera que ocurría a muchos kilómetros de distancia (11).

González, por su parte, construye unas memorias fragmentarias donde lo que se privilegia es el hecho de ser testigo de otro tiempo y copartícipe de una situación social e histórica que le ha correspondido vivenciar a los artistas provincianos de su generación y particularmente de Valparaíso:

Pienso que todos teníamos terror a despertar de nuestros sueños y locuras porque la realidad se nos presentaba como algo indomable y carecíamos de vigor para remover los obstáculos que nosotros mismos nos habíamos colocado. [...] Sabíamos que en este presente estábamos consumando el futuro y nos queríamos fuera de una sociedad que no habíamos entendido y habíamos ayudado a que nos repudiara (59).

De este modo, el grupo de artistas bohemios porteños que se rememoran en estos textos se encuentra al margen del orden social e histórico, percibiendo como lugar de su auténtica realización un Valparaíso solo reconocido como el espacio «...para nuestro etéreo mundo de ensueños y equivocaciones» (59-60).

A partir de esta confesión, el sujeto generaliza sobre lo que es ser porteño, interviniendo doxásticamente, en un intento por revalorizar a esta gente marginada, desconocida o ausente, mediante la adscripción de ella a un espacio que funda su existencia: «Es propio de porteños no desear, no ya el resto del mundo, ni tan siquiera otro lugar del territorio» (108). Para González, los porteños son los lugareños, que le recuerdan la incansable actividad de los gatos castrados, conquistadores del espacio natural, esto es, aquellos que nunca han abandonado el espacio local, el barrio, el cerro, que descubren y redescubren a diario en todos sus rincones y refugios, sin alejarse del sitio de las raíces cortas, donde terminarán por descansar sus huesos. Por esto, su evocación memorialística estrecha irremediablemente historia y paisaje, que entendemos como "hábitat interpretado, sometido a un horizonte simbólico» (Kusch 2000: 211). En González es el paisaje, como manifestación geocultural, el que determina la diferencia identitaria, ya desde los primeros relatos que conforman sus memorias: «La gente seguirá conversando, seguirá soñando, seguirá haciendo locuras, pero si no la acompaña el paisaje, todo será diferente» (González, 123).

Los relatos que componen las memorias de González revelan una suerte de escamoteo, de desaparición de una historia; se trata de anécdotas de vidas que caen en el vacío y cuya única forma de recuperación es la acción cotidiana que genera un espacio local 
defensivo, refugiándose en la melancólica nostalgia de lo que siempre «ya no es más». González asume esa ciudad que no es la de las postales, sino la que verdaderamente le correspondió vivir, así como para el profesor Maturana, en la novela de Uribe, la "ciudad que sería su taimada enemiga quizás por cuanto tiempo» (43), el puerto provinciano marginado, que se experimenta cotidianamente, con pobrezas y miedos, sin la ilusoria "poeticidad» con que la reviste el foráneo. De modo que la imagen de Valparaíso se va diseñando con aspectos esperpénticos y paradojales, donde su gente y lo tradicionalmente asociado al puerto se aprecian de un modo socarrón y definitivo, revelando la pérdida de una identidad local supuestamente tradicional de sus moradores, una identidad que estuvo asociada al mar, al puerto y sus faenas, al comercio, el progreso y la filantropía, a la modernidad trasplantada desde los centros europeos.

\section{«FOTOGRAFÍAS" DE OTRO VALPARAÍSO}

La articulación discursiva del espacio local, el espacio cotidiano, es uno de los aspectos determinantes de la escritura memorialística y de la novela locales. Efectivamente dicho espacio es existencial y concreto, "productor y producto de experiencias vividas» (De Nordenflycht, 2003: 50); no obstante, la alusión a zonas concretas de la ciudad, provoca más bien una resimbolización del lugar, en la medida que da cuenta de una mirada desde la cultura de lo cotidiano y del margen, retratando aquellos lugares que producen vivencias constructoras de un imaginario local, que va persistiendo en la memoria de los habitantes y que, por tanto, les proporciona identidad.

Entretejido con la construcción identitaria del sujeto como proceso de una vida testimoniante, el espacio se articula, en la trama discursiva de González, operando como lugar de encuadre y como punto de fuga para la actividad de contar y en este sentido el texto se hace homólogo a un álbum fotográfico, que cuando es abierto a los ojos de los otros, siempre debe responder a las preguntas ¿quiénes son ellos, dónde estaba ubicado esto o lo otro, cuándo ocurrió?, etcétera. Esa presencia del otro, que puede ser también, desdoblándose, el mismo yo, nos hace narrar, nos induce y conduce a través del placer de contar. Así parece que el relato de estas experiencias cotidianas, heterogéneas, caóticas, es provocado por una imaginación que busca en la memoria aquellas imágenes significativas, por alguna razón, que tal vez no es más que la cercanía de la muerte. De este modo, cada relato es una fotografía de uno o varios lugares; pero también son esos espacios los que generan la historia contada.

A partir de los espacios descritos, podemos visualizar la conformación de un imaginario urbano, que con apego a lo real, nos dibuja un mapa de la ciudad que experimenta el sujeto. Lo interesante de este diseño es la diferencia entre el Valparaíso «memorializado» por González y aquel que tradicionalmente se manifiesta en los múltiples textos que lo han intentado retratar. ${ }^{2}$ En ellos y tal vez en lo que la mayoría de la gente reconoce como singular de la ciudad puerto, la «fotografía» se concentra en sus cerros, en sus ascensores, en sus calles estrechas escaleras laberínticas, en el barrio del puerto, o en la imagen de la bahía enjoyada de luces nocturnas.

\footnotetext{
La mayoría de estos textos han sido recogidos en el libro de Alfonso Calderón, Memorial de Valparaíso.
} 


\section{EL BARRIO, EL «CERRO»: ESPACIO IDENTITARIO MARGINADO}

En la ciudad de las memorias de González, se hace patente un espacio urbano marginado de la imagen oficial de Valparaíso casi hasta su invisibilidad, pero que corresponde particularmente al estamento social del sujeto de esa época: el Barrio Almendral, con sus calles, casas y bares, espacios que comúnmente recorría la gente que vive la ciudad todos los días. Así, el espacio donde se desarrollan los acontecimientos relatados es un lugar que no interesa a los foráneos ni a los turistas que vienen de paso a Valparaíso, para quienes existiría una ciudad «oficial»; el Valparaíso de las postales, frente a la cual estas memorias revelan una ciudad «local», conocida sólo por los porteños.

En la configuración del discurso, ese espacio redefinido se comporta como una estructura esencial en la construcción identitaria del sujeto y por tanto de la comunidad local. Inicialmente el encuadre de tales espacios está dado por la contraposición sociohistórica entre espacios hegemónicos, de prevalencia política, social y cultural, manifiesta en diversas referencias a la capital, y las imágenes "poéticas», pintorescas, del puerto que no hacen más que trasladar la mirada hegemónica foránea, que lo exotiza. Frente a ello se construyen los espacios contrahegemónicos, de índole marginal, soterrada, sin poder político, social o cultural, que configuran la ciudad efectivamente experimentada por sus habitantes, un puerto provinciano, que apenas si mira al mar y ha enajenado el espacio comercial del puerto a otros.

La resimbolización de los espacios se operará desde lo que se vive como experiencias individuales y colectivas de aparente falta de significación. Esta cotidianidad nos habla de una identidad porteña que se relaciona con el «no desear» y por tanto con un no más allá de sus límites locales. En este sentido, los lugares descritos diseñan un mapa de lo que se descubre como el Valparaíso "profundo», que territorialmente queda circunscrito, por el texto de González, al barrio Almendral, cuya frontera terminaba en la acera poniente de la plaza O’Higgins. Más allá era otro pueblo, otra historia de marinos y protestantes, tierra de sajones enriquecidos por el comercio y el contrabando (90).

El espacio local del barrio, con sus edificaciones peculiares y caracterizadoras, toma un sentido sostenedor de la existencia plena y perenne, porque como afirma González «entonces no se edificaba hacia arriba; se construía hacia adentro, hacia la intimidad, hacia el corazón» (90). Salir de sus límites es perder la identidad. El tránsito por estos espacios da lugar al recuerdo de las experiencias acaecidas, de modo que el lugar se torna generador del anecdotario, y por tanto constructor de la historia del sujeto, surgida desde la necesidad de constituirse en un discurso contrahegemónico, dadas las circunstancias de marginación generadas por el discurso del proyecto de la modernidad asumido en América Latina desde la idea de naciones que despoja de entidad real a la escritura de provincia, situándola en una carencia identitaria que la obliga a someterse a la canonización metropolitana nacional so pena de no existir.

Junto al relevamiento del espacio, en estas memorias locales de González, los sueños diurnos se manifiestan como un recurso que de manera transversal cruza el proceso de identificación desde la etapa de la infancia hasta la adultez. El sueño adquiere a lo largo del relato dos sentidos: primero se concibe como manifestación del deseo de algo que no se quiere perder, funcionando en contraposición de lo real fáctico, de modo que lo que se vive en lo cotidiano es la construcción onírica de un grupo que no quiere enfrentar el término de una época, de un Valparaíso que comienza a desintegrarse para ellos; la realidad 
está de la mano con la modernización, y eso ahora se trasladó a Santiago. El despliegue del capitalismo no da pábulo a los grupos de asociación intermedia, sino a las vertientes verticales, donde el individuo resulta solo en apariencia ser libre. De manera que el sueño es un lugar de contención, un lugar donde las estructuras del presente no pueden acceder, el lugar donde no se vive la realidad, pero sí se puede vivir de verdad. Pero también, estos sueños se caracterizan por ser fantasías en estado de vigilia, de carácter no deseado, fantasías que denotan estados de insatisfacción, de falta de plenitud y que únicamente son retribuidos consoladoramente mediante la conversación.

Los intelectuales no tenían medios de difusión, el fuelle de la respiración nacional alcanzaba solo hasta Santiago. Para no asfixiarse, conversaban y conversaban. Pienso que todos teníamos terror a despertar de nuestros sueños y locuras porque la realidad se nos presentaba como algo indomable y carecíamos de vigor para remover los obstáculos que nosotros mismos nos habíamos colocado (González, 59).

González resume en una expresión de desaliento la desesperanza que tiñe el imaginario del medio siglo porteño: «Sentí todo el dolor de Valparaíso caminando impotente por Santiago» (200).

\section{MEMORIAS REGIONALES, NOVELA PROVINCIANA: ESCRITURAS DE RESISTENCIA}

Finalmente indiquemos que la escritura memorialística local y la novela provinciana, en tanto operan como un dispositivo capaz de integrar la actividad identitaria del sujeto con el espacio cotidiano (espacio de lo local) en el ámbito de un imaginario geocultural colectivo y diferencial, van constituyéndose en un mecanismo de Rettungen ${ }^{3}$ (salvaciones, salvamentos, rescates, liberaciones).

La (re)construcción de Valparaíso desde la escritura memorialística local de González y en la ficción novelesca de Uribe prospecta ciudades dentro de una ciudad cruzada por diversos grupos intermedios que respondiendo a las necesidades de identificación configuran en su conjunto un espacio local, desde el hábitat que los define como grupos contrahegemónicos. Esta construcción de lo local, fruto compartido de los imaginarios diferenciales y colectivos grupales, se pone en escena en la ritualización de lo vivido en lo cotidiano, a través de una fantasmagoría urbana que hace visible la existencia de lo subalterno, desatendiendo la polaridad funcional que instaura la modernidad entre público y privado, puesto que en la esfera de lo local la línea divisoria entre estos dos ámbitos es casi imperceptible.

Los relatos de ambos textos discurren las rutas locales de la carne (realidades) y el sueño (ilusiones) del «Valparaíso de ayer» que es puesto en la vitrina de un discurso te-

Slavoj Žižek hace presente un interesante comentario que realiza Adorno sobre el mecanismo de Rettung al caracterizar el modo de dirigir de Furtwangler, que estimamos muy adecuado al sentido que atañe importa a nuestra lectura de González y Uribe. Dice Adorno: "pretendía la salvación (Rettung) de algo que ya estaba perdido, recuperando mediante la interpretación lo que ésta empezó a perder en el momento de la desaparición de una tradición vinculante. Este intento le presta algo del esfuerzo excesivo que supone una invocación cuando lo que ésta persigue ya no está pura e inmediatamente presente. (Adorno, Musikalische Shriften VI, Frankfurt, Suhrkamp, 1984, pag. 469)». Citado por Žižek (en línea). 
rritorial urbano, demarcatorio y asentador de la identidad local en un desarrollo de su despliegue histórico.

En definitiva, la escritura memorialística local de González y la escritura ficcional de Uribe tienen ambas un efecto reactivo y resistente frente a una modernidad secularizadora del campo cultural y promotora del individualismo; un proyecto expansivo tendiente a propulsar la utilización de la naturaleza en una sociedad descargada de toda prescripción numinosa (García Canclini, 1989: 31). Por el contrario, la identidad local se afinca en la sacralización y mitificación de los espacios cotidianos, en la promoción de identificaciones gremiales, grupales, que reinventan un espacio con sus recorridos, en una suerte de trashumancia que atraviesa y enhebra los barrios de la ciudad y construye la novela memorial colectiva del Valparaíso de mediados del siglo XX como testimonio de esta resistencia.

El imaginario de la decadencia es entonces una propuesta contrahegemónica frente a una modernización secularizadora del campo cultural y promotora del individualismo. Si el campo social y cultural del Valparaíso decimonónico resulta signado por una suerte de prometeísmo, manifiesto en la figura del filántropo y también en la del activista anarquista, la decadencia no es más que su refinamiento. No se trata entonces de «otro» imaginario, sino de que el refinamiento, como sostiene Durand (y todos los decadentes, bohemios o no, han sido refinados), y la sobreimpregnación del refinamiento propicia la subversión. De ahí que Durand afirme que «todas las culturas demasiado refinadas, conscientes del inextricable enmarañamiento de los perfeccionismos siempre han aspirado a una regresión, y a veces a una regresión hasta la barbarie, o por lo menos lo salvaje» (2003: 104-5). Uribe y González desde esa bohemia, cuyo gran salvaje y marginado han entrevisto en el poeta Quiñónez (Galdames), parecen estar diciendo como el personaje colectivo del famoso poema de Cavafis:

Y ¿qué será ahora de nosotros sin bárbaros?

Esos hombres traían alguna solución después de todo (2002:159).

\section{REFERENCIAS}

Augé, Marc. (1992). Non-lieux. Introduction à une anthropologie de la surmodernité. París: Du Seuil.

Bajtín, Mijail. (1981). Forms of time and the chronotope in the novel. The dialogic imagination. Austin: University of Texas Press.

Calderón, Alfonso. (2001). Memorial de Valparaíso. Santiago: RIL.

Cavafis, Constantino. (2002). Treinta poemas. En José Ángel Valente. Cuaderno de Versiones. Edición bilingüe y traducción de José Ángel Valente. Barcelona: Galaxia Gutenberg.

De Certau, Michel. (1995). La invención de lo cotidiano 1. Artes de hacer. México D.F.: UIA-Iteso.

Deleuze, Gilles y Félix Guattari. (1978). Kafka. Por una literatura menor. México D.F.: Era. 
De Nordenflycht, Adolfo. (2003). Quiñones: poeta, olvidado y porteño. Literaturas regionales e imaginarios neoculturales en Chile. Estudios filológicos $\mathrm{N}^{\mathrm{o}} 38$. Valdivia: Universidad Austral de Chile.

Durand, Gilbert. (2003). Mitos y sociedades. Buenos Aires: Biblos.

García Canclini, Néstor. (1989). Culturas Híbridas. México D.F.: Grijalbo.

González, Alfredo. (1995). De carne y de sueño. Memorias del Valparaíso de ayer. Valparaíso: Universidad de Valparaíso.

González Martínez, Joaquín. (2008). La historia vivida en las representaciones espaciales: La conformación del espacio tzeltal-tzotzil. Veracruz: Atarazanas.

Kusch, Rodolfo. (2000). Geocultura del hombre americano. Obras completas. Tomo III. Rosario: Fundación Ross.

Maingueneau, Dominique. (1993). Le contexte de l'oeuvre litteraire. Enonciation, écrivain, societé. París: Dunod. Obtenido 12 julio 2008 desde <http: //pagesperso-orange. fr/dominique.maingueneau/overview.html>.

Ortiz, Renato. (1996). Otro territorio. Ensayos sobre el mundo contemporáneo. Buenos Aires: Universidad Nacional de Quilmes Editorial.

Robin, Regina. (1989). Literatura y biografía. Historia y Fuente Oral. No 1: 69.

Solar, Claudio. (2001). Historia de la literatura de Valparaíso. Valparaíso: Gran Fraternidad de Escritores y Artistas de Valparaíso.

Uribe Echeverría, Juan. (1973). Sabadomingo. Santiago: Quimantú/Gabriela Mistral.

Uribe de H., María Teresa. (1993). Los materiales de la memoria. La investigación cualitativa. ICFES-INER. Obtenido 18 octubre 2008 desde <http://camoc33.googlespages.com/estudiodelocalidades.pdf $>$.

Žižek, Slavoj. (2002). [Acto o melancolía]. ¿Quién dijo totalitarismo? Cinco intervenciones sobre el (mal) uso de una noción. Valencia: Pre-textos. Obtenido 20 diciembre desde <http://www.vivilibros.com/excesos/15-a-02.htm\#5>.

Recepción: enero de 2009

Aceptación: marzo de 2009 